\title{
A reflection on gender issues in elder abuse research: Brazil and Portugal
}

\author{
Uma reflexão sobre questões de gênero \\ na pesquisa de abuso de idosos: Brasil e Portugal
}

Patricia Brownell ${ }^{1}$

\footnotetext{
${ }^{1}$ Associate Professor

Emerita of Social Service at Fordham University(New York City) and Emerita Scholar, Ravazzin Center on Aging; President of the National Committee for the Prevention of Elder Abuse. New York City USA brownell@fordham.edu
}

\begin{abstract}
Neglect, abuse and violence against older women has not been a prominent focus of elder abuse research. This is in spite of the fact that from an international human rights perspective this is considered a gap in policy and practice addressing abuse across the lifespan. A review of the literature reveals three dominant paradigms for studying older women and abuse, all of which have the potential for marginalizing older women's experiences and needs. An emergent human rights perspective is discussed as a more holistic framework for understanding abuse of older women and ways of addressing this from an international perspective. Examples of research from Brazil and Portugal are reviewed and discussed.

Key words Neglect, Violence against older women
\end{abstract}

Resumo Negligência, abuso e violência contra mulheres mais velhas não tem sido um foco importante de pesquisa do abuso de idosos. Isto é, apesar do fato de que a partir de uma perspectiva internacional dos direitos humanos isso é considerado uma lacuna em políticas e práticas abordando abuso no decorrer da vida. Uma revisão da literatura revela três paradigmas dominantes para estudar as mulheres mais velhas e abusos, os quais têm o potencial para marginalizar experiências e necessidades das idosas. Uma perspectiva emergente de direitos humanos é discutida como um quadro mais holístico para a compreensão de abuso de mulheres mais velhas e formas de lidar com isso em uma perspectiva internacional. Exemplos de pesquisa do Brasil e Portugal são revistos e discutidos.

Palavras-chave Negligência, Violência contra as mulheres mais velhas 


\section{Brazil's role in the human rights movement for older people}

Brazil is among the world's leading countries in promoting an international human rights agenda for older people. From Brazil's perspective, older people are not an inherently vulnerable group but are subject to vulnerabilities due to situations of abuse and violence, and harmful stereotypes based on a negative social construction of old age ${ }^{1}$.

Currently, over 60 million people age 60 years and older live in Brazil, about 60 percent of the population ${ }^{2}$. To address this growing population of older adults, Brazil has modernized its legislation and national plans to incorporate provisions of the Madrid International Plan of Action on Ageing ${ }^{3}$ and has ensured that its institutional framework addresses the needs of elderly citizens from a rights-based perspective ${ }^{2}$.

Brazil hosted the Second Regional Intergovernmental Conference on Ageing in Latin America and the Caribbean, which resulted in the Brazilian Declaration ${ }^{4}$ and was one of the first countries to sign the Inter-American Convention on Protecting the Human Rights of Older Persons (2015). In both these documents, older people's right to be protected from violence was highlighted, and in particular, the responsibility of governments to "promote the elimination of all practices that generate violence and affect the dignity and integrity of older women" (Chapter IV, Article 9i). The vulnerability of older women to violence and discrimination is highlighted in both the Madrid International Plan of Action on Ageing $^{3}$ and the Inter-American Convention on Protecting the Human Rights of Older Persons ${ }^{4}$.

In November 2013, the United Nations Department of Economic and Social Affairs (DESA) convened an Expert Group Meeting (EGM) on neglect, abuse and violence against older women; with a commissioned discussion paper that reviewed published scholarship on this topic to date and 15 experts from around the world invited to attend and make recommendations for follow up ${ }^{5,6}$. Following is a summary of the findings from the discussion paper, and a review of selected published studies on abuse of older adults and older women specifically from Brazil and Portugal.

\section{Overview of different paradigms of abuse, neglect, and violence against older women}

There are three dominant conceptual frameworks for understanding neglect, abuse and violence against older women. These are intimate partner violence, active ageing, and vulnerable older adult. Intimate partner violence (IPV) refers to physical, sexual and psychological abuse (or threat of such abuse) and violence against women and girls that is perpetrated by intimate partners (including dating partners) as well as strangers and acquaintances in the case of sexual abuse. Using this theoretical framework to examine abuse of girls and women across the life course, researchers have found that older women experience significantly less abuse that younger women, suggesting that in this frame abuse of older women is not a significant problem compared to that of younger women and girls. Prevalence data for abuse of older women in the IPV frame range from $1-2 \%{ }^{6}$.

A different picture of abuse and violence against older women emerges when examined from an active ageing frame. In this frame, perpetrator categories expand to include not only spouse/partners, in addition adult children and grandchildren, other relatives, neighbors and friends, and caregivers. Like the intimate partner abuse perspective, victims are assumed to live in the community, but may not necessarily have an intimate partner relationship. Forms of abuse are also expanded in the frame to include, in addition to physical, sexual and psychological abuse, also financial or material exploitation, and neglect. Measures of psychological abuse may be expanded beyond threats of physical or sexual violence to include denigrating verbal abuse as well as non-verbal abuse in the form of social control behaviors like isolating and ignoring (or even treating the older woman as a child). Where available, prevalence data for abuse of older women in studies using the active ageing frame has been found to be as high as 38 percent $^{7}$.

A third perspective on abuse and violence against older women, the vulnerable older adult frame, assumes frailty and cognitive impairment leading to high levels of care dependency, necessitating protection to avoid victimization. The vulnerable older adult frame assumes that vulnerability of the older women in this category is based on inability to self-care or even supervise care. Victims are by definition care dependent, a criterion that is not necessarily relevant 
for the IPV or active ageing frames. Perpetrator categories are expanded to include not only family members and neighbors but also formal caregivers and other residents of care facilities as well ${ }^{8}$. Neglect as a form of abuse is highlighted in this frame, although sexual abuse by formal caregivers or other care facility residents is also of concern. This frame assumes the victim may not be able to report abuse because of cognitive or other impairments, so third party reports of abuse are utilized, creating some difficulty with data accessibility. Gender-specific prevalence data are largely unavailable to date for older women in protective settings.

While the intimate partner abuse frame, developed by the feminist domestic violence movement of the 1970's, was intended for younger women of reproductive age, intimate partner violence or domestic violence against older women, is informed by feminist gerontology and adapting a definition originally formulated by the USA Centers for Disease Control (CDC) ${ }^{9}$ uses a definition developed by the US Center for Disease Control (CDC) in the 1990s.

The active ageing frame is linked to a definition proposed in the Toronto Declaration on Elder Mistreatment ${ }^{10}$; the vulnerable older adult frame is informed by geriatrics using a definition that was formalized by the National Research Councill ${ }^{11}$; A fourth, a human rights perspective, is an emergent framework for examining abuse of older women, and is currently under development $^{12}$; (Bridget Sleap, Senior Policy Advisor, HelpAge International, Personal Communication, August 8, 2013).

Differing definitions have led to research findings, policy responses, and programs and practices that may appear contradictory and confusing to those not familiar with the field of elder abuse and neglect ${ }^{13}$. Each is linked to different assumptions and theoretical explanations for abuse of older women, and interventions including policies, programs and practices to prevent and end neglect, abuse and violence against older women. These have also challenged efforts to quantify neglect, abuse and violence against older women, as each are based on different assumptions, include different although sometimes overlapping variables, and lead to different findings on prevalence, ranging from as low as $1 \%$ to a high of $38 \%{ }^{6}$.

\section{Forms of abuse}

Main forms of abuse used to categorize mistreatment of older women include: physical, se- xual, psychological (also called emotional, verbal and non-physical) abuse, financial (also called material) exploitation, neglect, and violation of personal rights ${ }^{7}$. Different conceptual frameworks use a combination of different forms to operationalize abuse. The Active Ageing and (Vulnerable) Older Adult Protection frames use most of the forms cited above, with the possible exception of violation of personal rights, sometimes termed social abuse ${ }^{14}$. The Intimate Partner Violence (IPV) frame uses physical, sexual, and psychological forms of abuse, and sometimes violation of personal rights, but not neglect and usually not financial exploitation (unless included in a measure of psychological abuse) $)^{9}$.

Physical/Sexual: Some studies of older women and abuse categorize sexual abuse as a sub-set of physical abuse. Physical abuse includes actions intended to cause physical pain or injury to an older adult, such as pushing, grabbing, slapping, hitting, or assaulting with a weapon or thrown object. Sexual abuse can include offensive sexual behaviors as well as physical contact of a sexual nature ${ }^{10}$.

Psychological: This form of abuse is also called verbal or emotional abuse, which may be further defined as active or passive. This describes actions intended to inflict mental pain, anguish or distress on an older person ${ }^{7}$. Qualitative research studies have examined forms of psychological abuse against women in greater depth. Montminy $^{15}$ found 14 types of psychological abuse, which can be active or passive, perpetrated by intimate partners against older women. These include: control, denigrate, deprive, intimidate, threaten, abdicate responsibility, manipulate, blame, harass, negate victim's reality, sulk, infantilize, show indifference, and provoke guilt. In IPV studies, financial exploitation or material abuse (use of property or possessions without victims' permission) can be a subset of psychological abuse. Also in IPV research, psychological abuse may be limited to threats of physical or sexual violence.

Neglect: The National Research Council $(\mathrm{NRC})^{11}$ definition of elder abuse, with its inclusion of vulnerability as a core concept associated with victims, provides the most explicit link with neglect of older care dependent adults. This definition is further operationalized to include neglect as an "omission by responsible caregivers that constitutes 'neglect' under applicable federal or state law" and caregiver as "a person who bears or has assumed responsibility for providing care or living assistance to an adult in need of such 
care or assistance"11. It is further operationalized as refusal or failure of these responsible for providing a care-dependent older adult with assistance in daily living tasks or essential supports such as food, clothing, shelter, health and medical care. This can also include desertion of a care dependent older adult, also called abandonment ${ }^{10}$.

Financial exploitation and material abuse: This form of abuse describes actions of illegal or improper use of an older person's money, property or assets. Women have been found to be especially vulnerable to this form of abuse and were twice as likely to be victims of financial abuse as men in a recent study conducted in the $\mathrm{USA}^{16}$. Most victims in this study were between the ages of 80 and 89 years old, lived alone, and had some care needs that required help in their homes.

Violation of Personal Rights: Linked to the concept of individual human rights, this form of abuse includes the infringement of personal rights as a form of elder abuse ${ }^{7}$. It includes behaviors that violate an older person's right to privacy, right to autonomy and freedom, and right to have access to family and friends. This form of abuse has sometimes been referred to as social abuse $e^{14,17}$.

\section{Intimate Partner Violence (IPV) against Girls and Women of All Ages}

Intimate partner violence is defined as violence against women that "incorporates intimate partner violence (IPV), sexual violence by any perpetrator, and other forms of violence against women, such as physical violence committed by acquaintances or strangers ${ }^{18}$. This definition was developed by an expert panel convened by the United States Centers for Disease Control and Prevention in 1996 to formulate a uniform definition and recommended data elements for gathering surveillance data on intimate partner violence. It was intended to promote consistency in data collection for public health surveillance and as a technical reference for automation of the surveillance data ${ }^{19}$.

Operationalized data elements broaden the scope of this definition somewhat. The victim is anyone who is the target of violence or abuse. The perpetrator is the person who inflicts the violence or abuse or causes the violence or abuse to be inflicted on the identified victim. In this definitional set, the perpetrator is assumed to be an intimate partner, defined as current or former spouse or common-law spouse, and current or former non-marital partner including dating partner (heterosexual or same sex), boyfriend or girlfriend. Violence can include physical, sexual, threat of physical or sexual violence, and psychological or emotional abuse.

Psychological abuse is defined apart from threat of physical or sexual abuse to include humiliating the victim, controlling the victim's behavior, withholding information from the victim, getting annoyed if the victim disagrees with perpetrator, deliberately doing something that makes the victim feel diminished, using the victims' money, taking advantage of the victim, disregarding what the victim wants, isolating the victim from family or friends, prohibiting the victim's access to transportation or telephone, getting the victim to engage in illegal activities, using the victims' children to control victims' behavior, threatening loss of custody of children, smashing objects or destroying property, denying the victim access to money or other basic necessities, and disclosing information that would tarnish the victims' reputation. It also includes consequences such as impairment, injury, disability and use of health, mental health and substance abuse services ${ }^{19}$.

This conceptualization of abuse is not necessarily gender or age specific although it typically is applied to analyses of abuse and violence toward women of reproductive age. It does not define the victim as incapacitated or care dependent. Financial or material exploitation if included at all is defined as a form of psychological abuse. It assumes a power and control relationship between the victim and perpetrator. According to this definition, sexual abuse could be perpetrated by an acquaintance or stranger; physical abuse could be perpetrated by a one-time date. Study samples based on this conceptualization of abuse generally use age ranges from 18 or younger to 49 , presumed to be the end of reproductive age for women. Old age for these studies often start at 50 years of age,

\section{Active Ageing}

In the Toronto Declaration on the Global Prevention of Elder Abuse, elder abuse is defined as "a single or repeated act, or lack of appropriate action, occurring within any relationship where there is an expectation of trust which causes harm or distress to an older person. It can be of various forms: physical, psychological, emotional, sexual, and financial or simply reflect intentional or unintentional neglect" ${ }^{\prime 10}$. This is linked 
to the active ageing concept of older adulthood, in which older women and men are considered to have the capacity to be productive contributors to society ${ }^{3}$.

Violence against older women in this frame is often subsumed into gender neutral findings, with data on older women subjects aggregated with that on older men. An important exception is the set of studies on older women and abuse conducted in several countries of the European Union ${ }^{7}$.

The definition used in the Toronto Declaration originated with a United Kingdom NGO, Action on Elder Abuse in $1995^{20}$, and was adopted by an expert group on elder abuse from the International Network for the Prevention of Elder Abuse (INPEA) and the World Health Organization (WHO) that met in Toronto (Ontario), Canada in $2002^{10}$. Age of the victim is not defined as part of this definition but is usually 60 years of age and older in studies that use this definition, because they tend to focus on older adults living in the community. This definition used in elder abuse research, policy and practice formulation is influenced by social gerontology.

An example of a prevalence study conducted in Portugal in the active ageing frame is Prevalence Study of Violence and Abuse against Older Women: Results of the Portugal Study ${ }^{21}$. In this frame, survey questions are typically developed by experts and given to older adults, in this instance women age 60 years and older, living in the community, who are capable of responding usually without assistance. This same survey was conducted in several countries of the European Union: what is remarkable about the Portuguese findings is that the rate of self-reported abuse is remarkably high: 38 percent of respondents reported experiencing abuse in older age.

\section{Abuse of Vulnerable Adults (Older Adult Protection)}

Abuse of vulnerable older adults refers to "intentional actions that cause harm or create a serious risk of harm (whether or not harm is intended) to a vulnerable elder by a caregiver or other person who stands in a trust relationship to the elder, or failure by a caregiver to satisfy the elder's basic needs or protect the elder from harm"11.

This definition of elder abuse was developed by an expert panel (Panel to Review Risk and Prevalence of Elder Abuse and Neglect) convened by the National Research Council of the United States National Academy of Science for the purpose of creating a suggested uniform definition and operationalized data elements on elder abuse for research, policy, and program development and practice purposes. In this definition, self-neglect, victimization by strangers, and intimate partner abuse of older adults, unless vulnerability exists above and beyond old age, is not considered elder mistreatment ${ }^{22}$.

The conceptualization of elder abuse victims as frail, vulnerable, and care dependent older adults in need of protection falls under this definition. Studies using this framework often set the age of victims as 65 years of age and older.

\section{Human Rights and Abuse of Older People}

Human rights is a recent conceptual framework that was the subject of discussion in fora like the Expert Group Meeting on Neglect, Abuse and Violence of Older Women and the Elder Abuse Symposium sponsored by the Elder Abuse Interest Group at the 2013 Gerontological Society of America meeting. The human rights framework is believed by some elder abuse experts to hold promise for understanding neglect, abuse and violence against older women in a holistic way without the potential for fragmentation of other frameworks ${ }^{23}$.

While it is still too early to propose a human rights theory of neglect, abuse and violence against older women, some of the elements of such a theory can be tested using existing data. This includes applying a life course perspective using longitudinal data, and focusing on the experiences of older women specifically, not older people in general or women in general ${ }^{24}$. It also includes awareness of intersectionality, specifically related to gender and age, but also race/ethnicity, class, access to health and mental health, and relationships.

Including the concept of intersectionality begins to draw on a human rights framework. This states that human rights are interdependent and the level of enjoyment of any one right is dependent on the level of realization of the other rights. The Convention for the Elimination of all Forms of Discrimination Against Women (CEDAW) and the CEDAW General Recommendation No. 27 (human rights of older women) lay out the rights of older women to live lives of dignity free of discrimination and abuse ${ }^{25}$. Old age is presumed to begin at 60 years, the beginning of old age as defined by the United Nations.

The human rights framework defines older adults as rights bearers, because they have a right 
to live lives of dignity, free of abuse, and family members and caregivers as duty bearers, to explain their obligation to ensure that older adults to whom they are related or to whom they have a commitment to provide care. The State (government) is a duty enforcer, with the obligation to ensure that the rights of older people are upheld, and sometimes are duty bearers, when the State is directly responsible for older people's care. This framework identifies abuse, neglect and violence inclusive of poverty, traditional harmful practices, and discrimination based on age and gender, and institutional violence, making it broader than more academic and traditional definitions of neglect, abuse and violence against older adults.

\section{Discussion of Brazilian and Portuguese Scholarship on Elder Abuse}

This paper will review two studies of elder abuse conducted in Brazil and two in Portugal. These will be discussed in relation to the three dominant frames presented in this paper: intimate partner abuse, active ageing, and vulnerable older adult abuse.

\section{Intimate Partner Violence Frame}

A study of older Brazilian women's experience of psychological abuse falls within the intimate partner violence (IPV) frame ${ }^{26}$. It is an example of qualitative research, a methodology appropriate for examining abuse from a feminist perspective, in that it draws on the voices of older women who have experienced abuse, not the voices of professionals speaking on behalf of victims. This study illustrates an important perspective that not all elder abuse victims are frail, care dependent and elderly; and domestic violence can affect older women as well as younger ones in many different ways.

Psychological abuse has been identified as a prevalent form of abuse experienced by older women and has at times been minimized in the IPV literature. However the findings of this study are congruent with findings from similar studies in other parts of the world, in that the impact reported by subjects include negative health outcomes as well as feelings of sadness, grief, and fear $^{27}$. It also addresses what has been identified as a gap in studies of older adult abuse $\mathrm{e}^{28,29}$.

\section{Active Ageing Frame}

A study in the active ageing frame was conducted in Brazil by Machada et al. ${ }^{30}$ as part of a larger study by the International Network for the Prevention of Elder Abuse (INPEA) in partnership with the World Health Organization. This study used as subjects a sample of both older men and women age 60 years and older living in the community. Using a focus group methodology, interviewers representing health professionals asked older adults what to them represented elder abuse. While the study used typical categories of abuse such as physical, psychological, and financial as well as neglect, it found that older Brazilian subjects went beyond this categorization to include social exclusion, ageism, and societal abuse ${ }^{30}$.

An example of a prevalence study conducted in Portugal in the active ageing frame is Prevalence Study of Violence and Abuse against Older Women: Results of the Portugal Study ${ }^{21}$. In this frame, survey questions are typically developed by experts and given to older adults, in this instance women age 60 years and older, living in the community, who are capable of responding usually without assistance. This same survey was conducted in several countries of the European Union: what is remarkable about the Portuguese findings is that the rate of self-reported abuse is remarkably high: 38 percent of respondents reported experiencing abuse in older age. This suggests that cultural factors may influence perceptions of elder abuse.

\section{Vulnerable Older Adult Frame}

A study also conducted in Portugal reviewed records of alleged cases of abuse in nursing homes. Findings included a lower rate of physical abuse, relative to caregiver neglect, and neglect was associated with high levels of care dependency on the part of victims ${ }^{31}$. The sample included older adults age 65 and older, a typical age range for a study of elder abuse in the vulnerable older adults frame, and while there were more older women than older men reported among the identified victims, prevalence by gender was not estimated. A review of medical records by professionals was conducted, as opposed to interviews of subjects because as the authors noted, a high (47 percent) of the victims were unable to communicate. 


\section{Discussion}

The siloed conceptualizations of violence against older women present a fragmented picture of older women and abuse, challenging efforts to develop comprehensive policies and programs to prevent this important social problem. The evolving human rights framework has the potential to develop integrative strategies to prevent and intervene effectively in abusive situations when they occur.

Consider the life course of a single older woman as she moves from marriage or intimate partner relationship to widowhood where inter- generational relationships with adult children and grandchildren become salient, to compromised health that may necessitate in-home or institutional care. These stages may not even be linear, but may co-occur or occur in different sequences. New research methodologies are needed that collect and analyze longitudinal data, and research studies that capture form and prevalence of violence regardless of settings, providing new ways of understanding and addressing neglect, abuse and violence against older women regardless of fluctuating life circumstances ${ }^{32}$. These are examples of challenges for the future. 


\section{References}

1. Permanent Mission of Brazil to the United Nation (UN). Statement for the Open Ended Working Group on Ageing, Fifth Session - July 30, 2014. Washington: UN; 2014.

2. Patriota AA. Statement by H.E. Ambassador Antonio de Agular Patriota, Permanent Representative of Brazil to the United Nations. General Assembly Open-ended Working Group on Ageing, Sixth Session - July 14, 2015. Washington: United Nation; 2015.

3. United Nations (UN). Political Declaration and Madrid International Plan of Action on Aging. 2002. [cited 2013 Dec 1]. Available from: http://social.un.org/ index/Portals/0/ageing/documents/Fulltext-E.pdf

4. ECLAC, 2015. Inter-American convention on protecting the human rights of older persons. [cited 2016 Aug 6]. Available from: http://www.oas.org/en/sla/dil/ inter_american_treaties_A-70_human_rights_older_ persons.asp

5. United Nations Department of Economic and Social Affairs. Neglect, abuse and violence against older women, 2013. [cited 2016 Dec 20]. Available from: http:// undesadspd.org/Ageing/Resources/PapersandPublications.aspx

6. Brownell P. Preventing neglect, abuse and violence against older women. Global Cooperation Newsletter, October Issue. Entebbe: International Council of Social Welfare; 2013.

7. Luoma M-L, Koivusilta M, Lang G, Enzenhofer E, De Donder L, Verté D, Reingarde J, Tamutienne I, Ferreira -Alves J, Santos AJ, Penhale B. Prevalence study of abuse and violence against older women: results of a multicultural survey in Austria, Belgium, Finland, Lithuania and Portugal (European Report of the AVOW Project). Helsinki: National Institute of Health and Welfare (THL); 2011.

8. Rosen T, Pillemer K, Lachs M. Resident-to-resident aggression in long-term care facilities: an understudied problem. Aggression and Violent Behavior 2008; 13(2):77-87.

9. Saltzman LE, Fanslow JL, McMahon PM, Shelley GA Intimate partner violence surveillance: uniform definitions and recommended data elements, version 1.0. Atlanta: Centers for Disease Control and Prevention, National Center for Injury Prevention and Control; 2002.

10. World Health Organization (WHO). The Toronto declaration on the global prevention of elder abuse. Geneva: WHO; 2002.

11. National Research Council. Elder mistreatment: abuse, neglect, and exploitation in an aging America. Washington DC: The National Academies Press; 2003.

12. McDonald L. Discussant: Elder abuse, how frameworks and theories drive research, policy and practice. New Orleans: Gerontological Society of America Annual Meeting; 2013.

13. Anetzberger GJ. An update on the nature and scope of elder abuse. Generations 2012; 36(3):12-20.

14. Yan E, Tang CS. Prevalence and psychological impact of Chinese elder abuse. Journal of Interpersonal Violence 2001; 16:1158-1174.

15. Montminy L. Older women's experiences of psychological violence in their marital relationships. Journal of Gerontological Social Work 2005; 46(2):3-22.
16. MetLife. Crimes of occasion, desperation, and predation against America's elders. New York: MetLife Mature Market Institute; 2011.

17. Yan E, Chan KL. Prevalence and correlates of intimate partner violence among older Chinese couples in Hong Kong. International Geriatrics 2012; 24(9):1437-1446.

18. Goergen T, Beaulieu M. Criminological theory and elder abuse research - fruitful relationship or worlds apart? Ageing International 2010; 35(3):185-201.

19. Krug EG, Dahlberg LL, Mercy JA, Zwi AB, Lozano R, editors. World report on violence and health. Geneva: World Health Organization; 2002.

20. Biggs S, Haapala I. Theoretical development and elder mistreatment: spreading awareness and conceptual complexity in examining the management of socio -emotional boundaries. Ageing International 2010; 35(3):171-184

21. Ferreira-Alves J, Santos AJ. Prevalence study of violence and abuse against older women. Results of the Portugal survey [AVOW Project]. Braga: Minho University; 2011.

22. Lindenberg J, Westendorf RG, Kurrle S, Biggs S. Elder abuse an international perspective: exploring the context of elder abuse. Int Psychogeriatr 2013; 25(8):12131215.

23. United Nations Human Rights (UN). Human rights indicators: a guide to measurement and implementation. Geneva: UN; 2012.

24. McDonald L, Thomas C. Elder abuse through a life course lens. International Geriatrics 2013; 25(8):12351243.

25. United Nations (UN). Convention on the Elimination of all Forms of Discrimination Against Women: General recommendation no. 27 on older women and protection of their human rights. New York: UN; 2010.

26. Souto RQ, Merighi MAB, Gurunge S, Jesus MCP. Older Brazilian women's experience of psychological domestic violence: a social phenomenological study. International Journal for Equity in Health 2015; 14:44.

27. Whittaker T. Violence, gender and elder abuse: towards a feminist analysis and practice. Journal of Gender Studies 1995; 4(1):35-45.

28. Jönson H, Åkerström M. Neglect of elderly women in feminist studies of violence - a case of ageism? J Elder Abuse Negl 2004; 16(1):47-63.

29. Harbison J. Changing career of "elder abuse and neglect" as a social problem in Canada: learning form feminist frameworks? J Elder Abuse Negl 1999; 11(4):5980 .

30. Machada L, Gomes R, Xavier E. Report on elder abuse in Brazil. Rio de Janeiro: Candido Mendes University; 2001 .

31. Frazão SL, Correia AM, Norton P, Magalhães T. Physical abuse against elderly persons in institutional settings. J Forensic Leg Med 2015; 36:54-60.

32. Manjoo R. Violence and abuse against older persons in the public and private spheres. New York: Expert Group Meeting Human Rights of Older Persons; 2012.

Artigo apresentado em 15/07/2016

Aprovado em 17/08/2016

Versão final apresentada em 19/08/2016 